\title{
Cost of integrating assisted partner services in HIV testing services in Kisumu and Homa Bay counties, Kenya: a microcosting study
}

\author{
Beatrice Wamuti ${ }^{1 *}$, Monisha Sharma ${ }^{1}$, Edward Kariithi ${ }^{2}$, Harison Lagat ${ }^{2}$, George Otieno $^{2}$, Rose Bosire ${ }^{3}$, \\ Sarah Masyuko ${ }^{1,4}$, Mary Mugambi ${ }^{4}$, Bryan J. Weiner ${ }^{1}$, David A. Katz ${ }^{1}$, Carey Farquhar ${ }^{1,5,6}$ and Carol Levin ${ }^{1}$
}

\begin{abstract}
Background: HIV assisted partner services (aPS), or provider notification and testing for sexual and injecting partners of people diagnosed with HIV, is shown to be safe, effective, and cost-effective and was scaled up within the national HIV testing services (HTS) program in Kenya in 2016. We estimated the costs of integrating aPS into routine HTS within an ongoing aPS scale-up project in western Kenya.
\end{abstract}

Methods: We conducted microcosting using the payer perspective in 14 facilities offering aPS. Although aPS was offered to both males and females testing HIV-positive (index clients), we only collected data on female index clients and their male sex partners (MSP). We used activity-based costing to identify key aPS activities, inputs, resources, and estimated financial and economic costs of goods and services. We analyzed costs by start-up (August 2018), and recurrent costs one-year after aPS implementation (Kisumu: August 2019; Homa Bay: January 2020) and conducted time-and-motion observations of aPS activities. We estimated the incremental costs of aPS, average cost per MSP traced, tested, testing HIV-positive, and on antiretroviral therapy, cost shares, and costs disaggregated by facility.

Results: Overall, the number of MSPs traced, tested, testing HIV-positive, and on antiretroviral therapy was 1027 , 869,370 , and 272 respectively. Average unit costs per MSP traced, tested, testing HIV-positive, and on antiretroviral therapy were $\$ 34.54, \$ 42.50, \$ 108.71$ and $\$ 152.28$, respectively, which varied by county and facility client volume. The weighted average incremental cost of integrating aPS was $\$ 7,485.97$ per facility per year, with recurrent costs accounting for approximately $90 \%$ of costs. The largest cost drivers were personnel (49\%) and transport (13\%). Providers spent approximately 25\% of the HTS visit obtaining MSP contact information (HIV-negative clients: 13 out of 54 min; HIVpositive clients: 20 out of 96 min), while the median time spent per MSP traced on phone and in-person was 6 min and 2.5 hours, respectively.

Conclusion: Average facility costs will increase when integrating aPS to HTS with incremental costs largely driven by personnel and transport. Strategies to efficiently utilize healthcare personnel will be critical for effective, affordable, and sustainable aPS.

Keywords: Cost, Integration, HIV, Assisted partner services, Kenya, Microcosting

*Correspondence: bwamuti@uw.edu

${ }^{1}$ Department of Global Health, University of Washington, 325 9th Avenue, Box 359909, Seattle, WA 98104, USA

Full list of author information is available at the end of the article

\section{Introduction}

In Kenya, approximately 1.4 million people are living with HIV (PLWH), of whom an estimated $79.5 \%$ of individuals aged 15-64 years are aware of their status; with lower rates among men compared to women (72.6 vs 
82.7\%, respectively) [1]. The World Health Organization (WHO) recommends scaling up of assisted partner services to address this gap as part of a comprehensive package of testing and care for PLWH, particularly among men who have lower HIV testing rates and tend to start antiretroviral therapy later in the course of their illness compared to women $[1,2]$.

HIV partner services entails trained healthcare workers consenting individuals diagnosed with HIV (index clients) for names and contact information for all sex partners in the last three years to notify these partners of their potential exposure to HIV and linking them to testing and care services [2]. There are two main types of partner services. In client referral, providers encourage index clients to notify their sex partners of their potential exposure and encourage them to test for HIV. In assisted partner services (aPS), healthcare workers facilitate exposure notification after an agreed time if the index client does not notify their partner (contract referral), direct notification without the involvement of the index client (provider referral), or accompany and support index clients when they disclose their status and the potential HIV exposure to their partner (dual referral). Healthcare providers do not reveal the identity of the index to partners when they contact partners via phone calls requesting them to receive HIV testing services (HTS) at a facility, or travel to partners' homes or workplaces to offer HIV testing [2].

Previous research and implementation projects from sub-Saharan Africa (SSA) demonstrate that aPS is safe, acceptable, and effective in increasing the number of newly testing partners and partners testing HIV-positive compared to client referral [3-10]. In addition, aPS has also been shown to be cost-effective and affordable [11]. A budget impact analysis (BIA) in Kisumu County, Kenya demonstrated that aPS is affordable but its impact was highly sensitive to the level of uptake [12].

Kenya's Ministry of Health $(\mathrm{MOH})$ is integrating aPS into the national HTS program, where integration is defined as the creation of linkages between a new intervention (aPS) and existing programs (HTS) to improve healthcare delivery [13]. Estimating costs of integrating aPS into routine HTS programs is crucial for budgetary planning. Further, understanding how aPS costs vary by location and client volume is important in resource allocation. We sought to estimate aPS costs to provide guidance to program planners and providers introduce and scale up aPS in their health systems.

We evaluated the cost of integrating aPS in the HTS program in Kisumu and Homa Bay counties in Kenya by estimating the incremental costs associated with integrating aPS into routine HTS programs, including startup and recurrent costs. We estimated the average unit cost per male sex partner (MSP) traced, tested, testing HIV-positive, and on antiretroviral therapy (ART). We generated cost profiles of key inputs to identify the key drivers of aPS program costs. We also calculated disaggregated incremental costs, average unit costs per MSP, and median time spent on aPS by facility.

\section{Methods}

\section{Parent project and intervention description}

This microcosting analysis was conducted within in the aPS scale-up project (NIAID R01AI134130), a collaborative implementation science study between the Ministry of Health $(\mathrm{MOH})$ National AIDS and STI Control Program (NASCOP), PATH-Kenya and University of Washington, conducted in 31 health facilities in Kisumu and Homa Bay counties in western Kenya [14]. Details of the aPS scale-up project and its implementation procedures have been published [14]. The overall goal of the project was to implement and evaluate the effectiveness of aPS when integrated within routine HTS, and assess implementation outcomes including acceptability, demand, integration, implementation fidelity, and costs.

The aPS scale-up project focused on evaluating aPS as a strategy for increasing HIV testing among men [14]. Though aPS is offered to both male and female clients receiving HTS in Kenya, this project deliberately targeted adolescent girls and women and their partners to address challenges in finding men who are difficult to mobilize through other interventions and may increase the burden of HIV through risky sexual behavior if not tested and treated Briefly, female clients testing HIV-positive at participating facilities (female index clients) received information on aPS and were screened for eligibility by healthcare workers. Those eligible were $\geq 15$ years of age - those between 15 and 18 years were emancipated minors as per Kenya guidelines [15], newly diagnosed HIV-positive, at low risk of intimate partner violence (IPV), not pregnant, and had at least one sexual partner within the last 3 years. Participants were classified to have either low, moderate, or high IPV risk using the IPV screening tool adopted from the national APS guidelines [16]. Women at low risk of IPV did not fear IPV from their partner or had never experienced any form of IPV (emotional, physical, sexual). Pregnant women were excluded as they were considered a vulnerable population and were instead offered home-based couple counseling and testing.

Consenting female index clients were asked to provide names and contact information for all MSPs in the last three years, a process called partner elicitation. HTS providers contacted MSPs via phone and/or physical (in-person) tracing to notify them of their potential HIV exposure and offer HIV testing. MSPs testing 
HIV-positive were asked to enroll in aPS and provide contact information for their female sex partners, who were also followed up, notified of their exposure, and offered HTS. Female index clients and sex partners testing HIV-positive were encouraged to link to care and followed up at 6 weeks, 6 months, and 12 months to assess linkage to care, ART initiation, and HIV viral load suppression.

\section{Cost data collection}

We estimated the incremental financial and economic costs of integrating aPS into the HTS program using a payer perspective [17] following principles outlined in the Global Health Cost Consortium Reference Case [18]. Financial costs represent actual expenditure on goods and services, while economic costs reflect the value of resources used to produce output. We used activitybased ingredients approach to identify key aPS activities, inputs, resource use, and associated prices and values of goods and services. We identified key activity cost centers and used microcosting methods to quantify and value inputs from each activity across facilities.

Cost data were collected during three field visits. In August 2018, we collected start-up costs from $\mathrm{MOH}$ NASCOP and PATH offices associated with one-time planning, training and awareness activities that took place before the project started. We then collected recurrent costs one year after study initiation from 14 facilities in Kisumu $(n=8)$ in August 2019, and then in Homa Bay $(n=6)$ in January 2020. Facilities were purposefully sampled based on location (county, urban/peri-urban/rural) and client volume (based on patient volumes receiving HTS at the facilities) after consultation with the site team.

We extracted data from project expense reports and $\mathrm{MOH}$ budgets, and obtained supplementary information on all key activities and resource use for the aPS integration. We also conducted semi-structured interviews with key health personnel at the $\mathrm{MOH}$ and $\mathrm{PATH}$, as well as facility administrators to obtain information on time use and shared program costs (rent, personnel salaries, and supply prices from $\mathrm{MOH}$ sources) that were not available from expense and budget reports. We disaggregated costs by facility to evaluate variations in incremental costs and average unit cost per MSP.

We included health system costs incurred during provider elicitation of MSPs from female index clients, as well as for phone and physical tracing for MSPs. We excluded costs of eliciting and tracing female sex partners of HIV-positive MSPs as this was not the primary focus of the costing analysis. We included the costs of HIV testing and linking MSPs testing HIV-positive to care, but did not include the costs of ART since these costs are incurred under the national HIV care and treatment program, which is separate from the HTS/aPS program. We also excluded the cost of research activities not part of routine aPS delivery.

\section{Cost analysis}

We differentiated between new aPS costs, and shared program costs to support the integration of aPS services into the existing HTS program. New costs were those related to aPS inputs and activities not conducted prior to aPS scale-up e.g., aPS microplanning meetings, initial trainings, sensitization, transport costs for physical tracing, communication costs for phone tracing, personnel (service delivery including partner elicitation, phone and physical tracing, exposure notification, HIV testing, and linkage to care) and aPS supervision. Shared program costs from the current HTS program were allocated based on the share of the activity or input used in aPS. These included the share of program costs for vehicles, equipment, overheads, HTS supplies, health facility administration, and refresher training.

We distinguished between fixed and variable costs. Fixed costs included overheads (e.g. building costs, water, and electricity), capital (vehicles, equipment), and non-service delivery personnel costs (i.e. health facility administration and aPS supervision). We allocated building space based on the proportion of time in the HTS visit taken up by aPS activities at each facility. Rental costs were estimated from $\mathrm{MOH}$ rates for government facilities or rental rates from nearby commercial properties. Capital costs were annualized over the expected useful life (assumed to be five years) using a 3\% annual discount rate [18]. Similarly, start-up costs (microplanning, sensitization and training), which occurred once during the project, were treated as a type of fixed costs and annualized over five years using a $3 \%$ discount rate.

We estimated variable costs by measuring resource use across the 14 facilities. Personnel time was captured as a proportion of full-time work allocated to aPS. Salaries were converted into hourly wages based on the assumption that full-time employment was equivalent to 2080 hours/year. We estimated personnel time using time-and-motion observation for partner elicitation at the clinic, and MSP outreach by phone and physical tracing. To estimate personnel time cost, we multiplied the cost per minute (including both salary and benefits) by the median time spent on aPS activities including: 1 ) partner elicitation by the number of female index clients seen, 2) phone tracing by the number of MSPs traced on phone accounting for approximately $40 \%$ repeat calls, and 3) physical tracing multiplied by the number of MSPs traced physically accounting for $10 \%$ repeat physical tracing attempts. Based on facility data reports, we assumed 
that of the MSPs who were successfully traced, $70 \%$ were traced on phone and $30 \%$ by physical tracing. Estimates for the phone calls and physical tracing attempts were based on facility reports and staff opinion.

Phone call costs were estimated as a percentage of airtime assigned to the facility per year used to call MSPs elicited through aPS. Transport costs were estimated by multiplying the number of expected commutes per year, mainly through public transport, by the average cost of each commute. For supplies and commodity costs, we observed resource use during HIV testing and multiplied the relevant quantities by input costs obtained from program budgets or centralized price lists.

Cost data were collected and analyzed in templates designed in Microsoft Excel (Microsoft, Redmond, USA). We adjusted costs to 2019 currency and converted to US dollars (USD) using the 2019 average exchange rate (1 USD $=$ KSh 101) [19]. Additional details about the costing methodology, including the Excel file used for the analysis, are available in the Supporting Information.

\section{Program volume}

We used data collected by the implementation project staff to obtain the number of MSPs traced, tested, tested HIV-positive, and on ART over a one-year period as recorded in the MOH HTS facility registers. These data were compiled from April 1, 2019 to March 31, 2020 to capture costs at least one year prior to the COVID-19 pandemic.

\section{Cost metrics}

For each facility, we first estimated incremental costs by summing the start-up and recurrent costs. We then calculated the average unit cost per MSP traced, tested, testing HIV-positive, and on ART by dividing the incremental costs by the number of MSPs traced, tested, testing HIV-positive, and on ART, respectively. Lastly, we estimated the weighted average incremental facility cost per year by weighting the annual incremental costs in our sample of 14 facilities by the number of MSPs in each facility. We also explored all cost metrics by facility to assess how client volume and location affect total incremental and average unit costs per MSP. We estimated cost shares by activity and input to explore how resources and activities were utilized within aPS.

\section{Scenario analysis}

We estimated the costs of integrating aPS under two scenarios: 1) as-implemented, which replicates the current national HTS program where financial support is received from both government and external funding sources, and 2) $\mathrm{MOH}$-only, in which, based on expert opinion from $\mathrm{MOH}$ and site staff, we excluded costs associated with international non-governmental organizations (NGO) i.e., we assumed that all HTS providers transitioned into the $\mathrm{MOH}$ human resource system, that only $\mathrm{MOH}$ staff would supervise aPS delivery, and that no international NGO overhead costs were incurred.

\section{Ethical approval}

This study received ethical approval from the Kenyatta National Hospital Ethical and Scientific Review Committee (P465/052017) and the University of Washington Institutional Review Board (STUDY00002420). This study was conducted in accordance with the Declaration of Helsinki, and all study participants gave informed consent for enrolment and follow-up prior to study participation.

\section{Results \\ Program volume}

The total number of MSPs traced, tested, testing HIVpositive, and on ART across the 14 facilities as well as the number of clients reached through aPS over the oneyear study period did not differ substantially by county (Table 1). These MSPs were elicited from 710 female index clients (Kisumu: 379 [53\%], Homa Bay: 331 [47\%]).

\section{Personnel time associated with integrating aPS into HTS}

Providers spent approximately $25 \%$ of an HTS visit with a newly diagnosed index client conducting partner elicitation i.e. obtaining MSP contact information (HIV-negative clients: 13 out of $54 \mathrm{~min}$; HIV-positive clients: 20 out of $96 \mathrm{~min}$ ) (Table 2). The median time spent per MSP traced on phone and in-person was 6 min and 2.5 hours, respectively. More time was spent on physical tracing in

Table 1 Program volume overall and by county

\begin{tabular}{|c|c|c|c|c|c|c|}
\hline Program volume & Kisumu & $\% *$ & Homa Bay & $\% *$ & Overall & $\% *$ \\
\hline Male sex partners traced & 1027 & $49 \%$ & 1048 & $51 \%$ & 2075 & $100 \%$ \\
\hline Male sex partners tested & 869 & $53 \%$ & 763 & $47 \%$ & 1632 & $100 \%$ \\
\hline Male sex partners testing HIV-positive & 370 & $55 \%$ & 298 & $45 \%$ & 668 & $100 \%$ \\
\hline Male sex partners on ART & 272 & $56 \%$ & 215 & $44 \%$ & 487 & $100 \%$ \\
\hline
\end{tabular}

*\% Row percentage, ART antiretroviral therapy 
Table 2 Median time spent per client on aPS-related activities

\begin{tabular}{|c|c|c|c|c|c|c|c|c|}
\hline \multirow[b]{2}{*}{ Health facility } & \multicolumn{3}{|c|}{$\begin{array}{l}\text { Median time spent on partner elicitation } \\
\text { among HIV-negative female index } \\
\text { clients receiving HIV testing services } \\
\text { (per client) }\end{array}$} & \multicolumn{3}{|c|}{$\begin{array}{l}\text { Median time spent on partner elicitation } \\
\text { among HIV-positive female index clients } \\
\text { receiving HIV testing services (per client) }\end{array}$} & \multirow[b]{2}{*}{$\begin{array}{l}\text { Median time } \\
\text { spent phone } \\
\text { tracing per client } \\
(\min )\end{array}$} & \multirow[b]{2}{*}{$\begin{array}{l}\text { Median time } \\
\text { spent physical } \\
\text { tracing } \\
\text { per client } \\
\text { (min) }\end{array}$} \\
\hline & $\begin{array}{l}\text { Partner } \\
\text { elicitation } \\
\text { (min) }\end{array}$ & $\begin{array}{l}\text { Partner elicitation } \\
+ \text { HIV testing } \\
\text { services (min) }\end{array}$ & $\%^{a}$ & $\begin{array}{l}\text { Partner } \\
\text { elicitation } \\
\text { (min) }\end{array}$ & $\begin{array}{l}\text { Partner elicitation } \\
+ \text { HIV testing } \\
\text { services (min) }\end{array}$ & $\%^{\mathrm{a}}$ & & \\
\hline \multicolumn{9}{|l|}{ Kisumu County } \\
\hline $\begin{array}{l}\text { Sub-county } \\
\text { hospital KH1 }\end{array}$ & 12 & 50 & $24 \%$ & 27 & 107 & $25 \%$ & 6 & 125 \\
\hline $\begin{array}{l}\text { Sub-County } \\
\text { hospital KL6 }\end{array}$ & 22 & 73 & $30 \%$ & 27 & 110 & $27 \%$ & 10 & 148 \\
\hline $\begin{array}{l}\text { Health center } \\
\text { KL5 }\end{array}$ & 3 & 16 & $19 \%$ & 3 & 16 & $19 \%$ & 5 & 163 \\
\hline $\begin{array}{l}\text { Health Center } \\
\text { KL4 }\end{array}$ & 13 & 50 & $26 \%$ & 15 & 119 & $17 \%$ & 4 & 185 \\
\hline $\begin{array}{l}\text { Health Center } \\
\text { KL7 }\end{array}$ & 8 & 36 & $22 \%$ & 13 & 57 & $23 \%$ & 6 & 153 \\
\hline $\begin{array}{l}\text { Sub-county } \\
\text { hospital KH3 }\end{array}$ & 12 & 84 & $14 \%$ & 27 & 126 & $19 \%$ & 13 & 202 \\
\hline $\begin{array}{l}\text { Health center } \\
\text { KL8 }\end{array}$ & 16 & 83 & $19 \%$ & 34 & 120 & $25 \%$ & 10 & 194 \\
\hline $\begin{array}{l}\text { Health Center } \\
\mathrm{KH} 2\end{array}$ & 10 & 39 & $26 \%$ & 10 & 39 & $26 \%$ & 9 & 307 \\
\hline Median (Kisumu) & 12 & 50 & $24 \%$ & 21 & 109 & $19 \%$ & 6 & 174 \\
\hline \multicolumn{9}{|l|}{ Homa Bay County } \\
\hline $\begin{array}{l}\text { Health Center } \\
\mathrm{HH} 2\end{array}$ & 17 & 66 & $26 \%$ & 37 & 106 & $31 \%$ & 5 & 114 \\
\hline $\begin{array}{l}\text { Sub-county } \\
\text { hospital HH3 }\end{array}$ & 15 & 60 & $25 \%$ & 20 & 92 & $23 \%$ & 8 & 97 \\
\hline Dispensary HL6 & 9 & 53 & $17 \%$ & 19 & 81 & $21 \%$ & 3 & 155 \\
\hline $\begin{array}{l}\text { County hospital } \\
\mathrm{HH} 1\end{array}$ & 17 & 56 & $31 \%$ & 30 & 88 & $32 \%$ & 9 & 137 \\
\hline $\begin{array}{l}\text { Sub-county } \\
\text { hospital HL5 }\end{array}$ & 15 & 59 & $25 \%$ & 20 & 73 & $26 \%$ & 8 & 114 \\
\hline Dispensary HL4 & 9 & 53 & $17 \%$ & 14 & 75 & $18 \%$ & 2 & 170 \\
\hline $\begin{array}{l}\text { Median (Homa } \\
\text { Bay) }\end{array}$ & 15 & 57 & $26 \%$ & 20 & 84 & $23 \%$ & 6 & 125 \\
\hline Overall median & 13 & 54 & $25 \%$ & 20 & 96 & $21 \%$ & 6 & 150 \\
\hline Range (Min-Max) & $3-22$ & $16-84$ & $14-31 \%$ & $3-37$ & $16-126$ & $17-32 \%$ & $2-13$ & $97-307$ \\
\hline
\end{tabular}

a \% Percentage

Kisumu compared to Homa Bay (174 min vs $125 \mathrm{~min}$ ) while minimal differences were noted in median time spent on partner elicitation and phone tracing in both counties.

\section{Incremental costs of integrating aPS}

The weighted average incremental cost of aPS was $\$ 7,485.97$ per facility per year (as-implemented), with recurrent costs accounting for approximately $90 \%$ of costs (Table 3). Personnel (49\%) accounted for the largest share of costs followed by transport (13\%). The proportion of costs appropriated to different categories was similar in both counties apart from personnel costs, which accounted for $54 \%$ of incremental costs in Kisumu, compared to just 35\% in Homa Bay, mainly due to differences in personnel time spent on physical tracing.

After excluding international NGO costs (MOH-only scenario), the weighted average incremental cost of integrating aPS was $\$ 5,494.06$ per facility per year. The reduction in costs was due to a decrease in personnel costs 
Table 3 Annual average weighted incremental facility cost - As implemented vs MOH-only scenario (2019 USD)

\begin{tabular}{|c|c|c|c|c|c|c|c|c|c|c|c|c|}
\hline & \multicolumn{6}{|c|}{ As implemented } & \multicolumn{6}{|c|}{$\mathrm{MOH}-$ only scenario } \\
\hline & Kisumu & $\%$ & Homa Bay & $\%$ & Overall & $\%$ & Kisumu & $\%$ & Homa Bay & $\%$ & Overall & $\%$ \\
\hline \multicolumn{13}{|l|}{ Start-up costs } \\
\hline Microplanning & $\$ 483$ & $5 \%$ & $\$ 432$ & $9 \%$ & $\$ 459$ & $6 \%$ & $\$ 483$ & $7 \%$ & $\$ 432$ & $12 \%$ & $\$ 459$ & $8 \%$ \\
\hline Initial Training & $\$ 466$ & $5 \%$ & $\$ 416$ & $9 \%$ & $\$ 443$ & $6 \%$ & $\$ 466$ & $7 \%$ & $\$ 416$ & $11 \%$ & $\$ 443$ & $8 \%$ \\
\hline Sensitization & $\$ 90$ & $1 \%$ & $\$ 17$ & $0 \%$ & $\$ 56$ & $1 \%$ & $\$ 90$ & $1 \%$ & $\$ 17$ & $0 \%$ & $\$ 56$ & $1 \%$ \\
\hline Sub-total & $\$ 1,040$ & $10 \%$ & $\$ 865$ & $18 \%$ & $\$ 958$ & $13 \%$ & $\$ 1,040$ & $15 \%$ & $\$ 865$ & $23 \%$ & $\$ 958$ & $17 \%$ \\
\hline \multicolumn{13}{|l|}{ Recurrent costs } \\
\hline Personnel & $\$ 5,407$ & $54 \%$ & $\$ 1,632$ & $35 \%$ & $\$ 3,642$ & $49 \%$ & $\$ 3,213$ & $46 \%$ & $\$ 1,215$ & $33 \%$ & $\$ 2,279$ & $41 \%$ \\
\hline HTS supplies & $\$ 573$ & $6 \%$ & $\$ 500$ & $11 \%$ & $\$ 539$ & $7 \%$ & $\$ 573$ & $8 \%$ & $\$ 500$ & $13 \%$ & $\$ 539$ & $10 \%$ \\
\hline Equipment & $\$ 28$ & $0 \%$ & $\$ 29$ & $1 \%$ & $\$ 28$ & $0 \%$ & $\$ 28$ & $0 \%$ & $\$ 29$ & $1 \%$ & $\$ 28$ & $1 \%$ \\
\hline Vehicles & $\$ 215$ & $2 \%$ & $\$ 0$ & $0 \%$ & $\$ 114$ & $2 \%$ & $\$ 215$ & $3 \%$ & $\$ 0$ & $0 \%$ & $\$ 114$ & $2 \%$ \\
\hline Transport & $\$ 1,260$ & $13 \%$ & $\$ 695$ & $15 \%$ & $\$ 996$ & $13 \%$ & $\$ 1,260$ & $18 \%$ & $\$ 695$ & $19 \%$ & $\$ 996$ & $18 \%$ \\
\hline Communication & $\$ 165$ & $2 \%$ & $\$ 40$ & $1 \%$ & $\$ 107$ & $1 \%$ & $\$ 165$ & $2 \%$ & $\$ 40$ & $1 \%$ & $\$ 107$ & $2 \%$ \\
\hline Overhead & $\$ 758$ & $8 \%$ & $\$ 580$ & $12 \%$ & $\$ 675$ & $9 \%$ & $\$ 72$ & $1 \%$ & $\$ 18$ & $0 \%$ & $\$ 46$ & $1 \%$ \\
\hline Refresher training & $\$ 489$ & $5 \%$ & $\$ 355$ & $8 \%$ & $\$ 426$ & $6 \%$ & $\$ 489$ & $7 \%$ & $\$ 355$ & $10 \%$ & $\$ 426$ & $8 \%$ \\
\hline Sub-total & $\$ 8,896$ & $90 \%$ & $\$ 3,831$ & $82 \%$ & $\$ 6,528$ & $87 \%$ & $\$ 6,015$ & $85 \%$ & $\$ 2,851$ & $77 \%$ & $\$ 4,536$ & $83 \%$ \\
\hline Summary & $\$ 9,935$ & $100 \%$ & $\$ 4,696$ & $100 \%$ & $\$ 7,486$ & $100 \%$ & $\$ 7,055$ & $100 \%$ & $\$ 3,717$ & $100 \%$ & $\$ 5,494$ & $100 \%$ \\
\hline
\end{tabular}

*\% Percent of total costs

specifically aPS supervision costs (from 49 to $41 \%$ ) and overheads especially rental leases for NGO offices (from $9 \%$ to $1 \%$ ) (Table 3 ).

\section{Average unit costs per MSP}

The average unit cost per MSP traced, tested, testing HIV-positive, and on ART (as-implemented) was \$34.54, $\$ 42.50, \$ 108.71$, and $\$ 152.28$, respectively (Table 4). These costs were much higher in Kisumu compared to Homa Bay County due to differences in personnel time spent on physical tracing. In the $\mathrm{MOH}$-only scenario, the average unit costs per MSP traced, tested, testing HIVpositive, and on ART were $\$ 25.55, \$ 31.59, \$ 81.42$, and $\$ 114.17$, respectively, largely due to lower personnel and international NGO overhead costs (Table 4).

\section{Direct aPS activity costs and shared program costs}

APS program specific delivery costs accounted for $74 \%$ of the incremental costs of aPS, while the remainder were shared costs related to overhead, training, administration, and supply costs of the existing HTS program (Fig. 1). For aPS delivery activities, the largest cost drivers were personnel and transport in both counties. However, direct aPS delivery costs were higher in Kisumu compared to Homa Bay County (77\% versus 66\%) mainly due to more personnel time spent on physical tracing.

\section{Fixed and variable costs}

Overall, costs were evenly split into fixed to variable costs, with no difference in shares between the two counties (Fig. 2).

\section{Costs by facility}

When exploring costs and outputs by facility, the total incremental costs varied substantially, from $\$ 630.06$ to $\$ 15,572.24$ per facility per year, while the average unit cost per MSP testing HIV-positive ranged from \$24.56 to $\$ 157.52$. Generally, the highest incremental costs

Table 4 Average unit cost per MSP - As implemented vs MOH-only scenario (2019 USD)

\begin{tabular}{|c|c|c|c|c|c|c|}
\hline \multirow[b]{2}{*}{ Average unit cost } & \multicolumn{3}{|c|}{ As implemented } & \multicolumn{3}{|c|}{$\mathrm{MOH}-$ only scenario } \\
\hline & Kisumu & Homa Bay & Overall & Kisumu & Homa Bay & Overall \\
\hline Cost per male sex partner traced & $\$ 46.56$ & $\$ 20.86$ & $\$ 34.54$ & $\$ 33.42$ & $\$ 16.60$ & $\$ 25.55$ \\
\hline Cost per male sex partner tested & $\$ 54.96$ & $\$ 28.30$ & $\$ 42.50$ & $\$ 39.51$ & $\$ 22.57$ & $\$ 31.59$ \\
\hline Cost per male sex partner testing HIV-positive & $\$ 135.29$ & $\$ 78.44$ & $\$ 108.71$ & $\$ 97.79$ & $\$ 62.78$ & $\$ 81.42$ \\
\hline Cost per male sex partner on ART & $\$ 183.02$ & $\$ 117.26$ & $\$ 152.28$ & $\$ 131.82$ & $\$ 94.07$ & $\$ 114.17$ \\
\hline
\end{tabular}

* ART Antiretroviral therapy 


\section{Direct aPS activity costs (74\%) - Shared costs with HTS (26\%)}
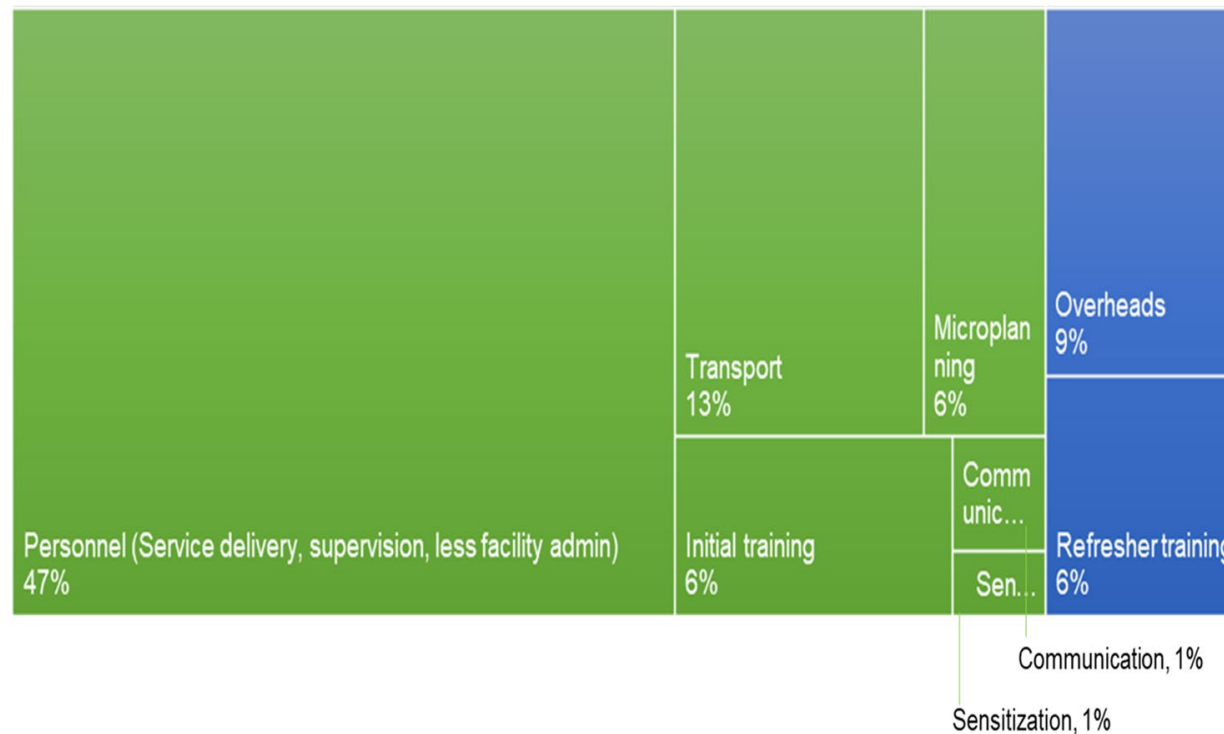

Fig. 1 Direct aPS activity costs compared to shared program costs of integrating aPS into HTS

and lowest average unit costs per MSP were observed in larger volume facilities, particularly county and subcounty hospitals, which had higher client volumes (Figs. 3 and 4).

\section{Discussion}

In this microcosting analysis, we estimate that integrating aPS into HIV testing services in Kisumu and Homa Bay county facilities targeting MSPs to female index clients would increase overall HTS cost by approximately $\$ 7,485$ per facility per year, mostly driven by recurrent costs (especially personnel and transport). The estimated annual budget at a high-volume county referral hospital in Kisumu is $\$ 720,000$, and facility-level aPS integration accounts for approximately $1 \%$ of the budget; therefore, aPS may be affordable in such a large facility, but may be less so in lower volume healthcare facilities with smaller budgets. We estimated higher incremental and lower average unit costs per MSP in larger volume facilities, which is expected as aPS implementation is more costly per client in low volume clinics since overhead costs are spread over fewer clients. This may highlight the need to prioritize resources towards higher volume facilities that can then support aPS in multiple low volume facilities within their vicinity to increase efficiency; however, this may lead to missed opportunities for aPS in lower volume facilities. The majority of the integration costs were direct aPS costs related to personnel (service delivery, aPS supervision) and transport, with approximately $25 \%$ of aPS integration costs shared with the existing HTS program (overhead, HTS supplies, refresher training), indicating the proportion of pre-existing HTS resources that would be needed to support aPS. Based on staff opinion, this $26 \%$ did not seem to overwhelm the facility healthcare system; they reported that aPS led to more optimal use of facility resources as more clients could be targeted to receive not only HTS, but also other available healthcare services (Personal communication).

Across facilities, personnel made up the largest portion of total costs (49\%), followed by transport (13\%). Kisumu County had higher personnel costs than Homa Bay as HTS providers spent more time physically tracing partners in Kisumu - where MSPs were harder to trace since they more frequently changed their places of work and residence, compared to those in Homa Bay - a rural county where clients change residence less often. This finding is consistent with qualitative results on aPS from our study [20]. The higher personnel and transport costs for MSP tracing highlight the importance of identifying methods to increase efficiency, e.g. batching visits, reducing distance traveled by HTS providers, utilizing community health workers or volunteers (CHWs, CHVs) to support physical tracing, incentivizing partners to come to the clinic for testing, and improving their mobile phone access.

This study complements previous estimates by providing an accurate estimate of the resources needed to scale up aPS as part of a routine HTS program in Kenya. Our unit cost estimates were slightly lower to prior studies that estimated aPS implementation cost as part of 


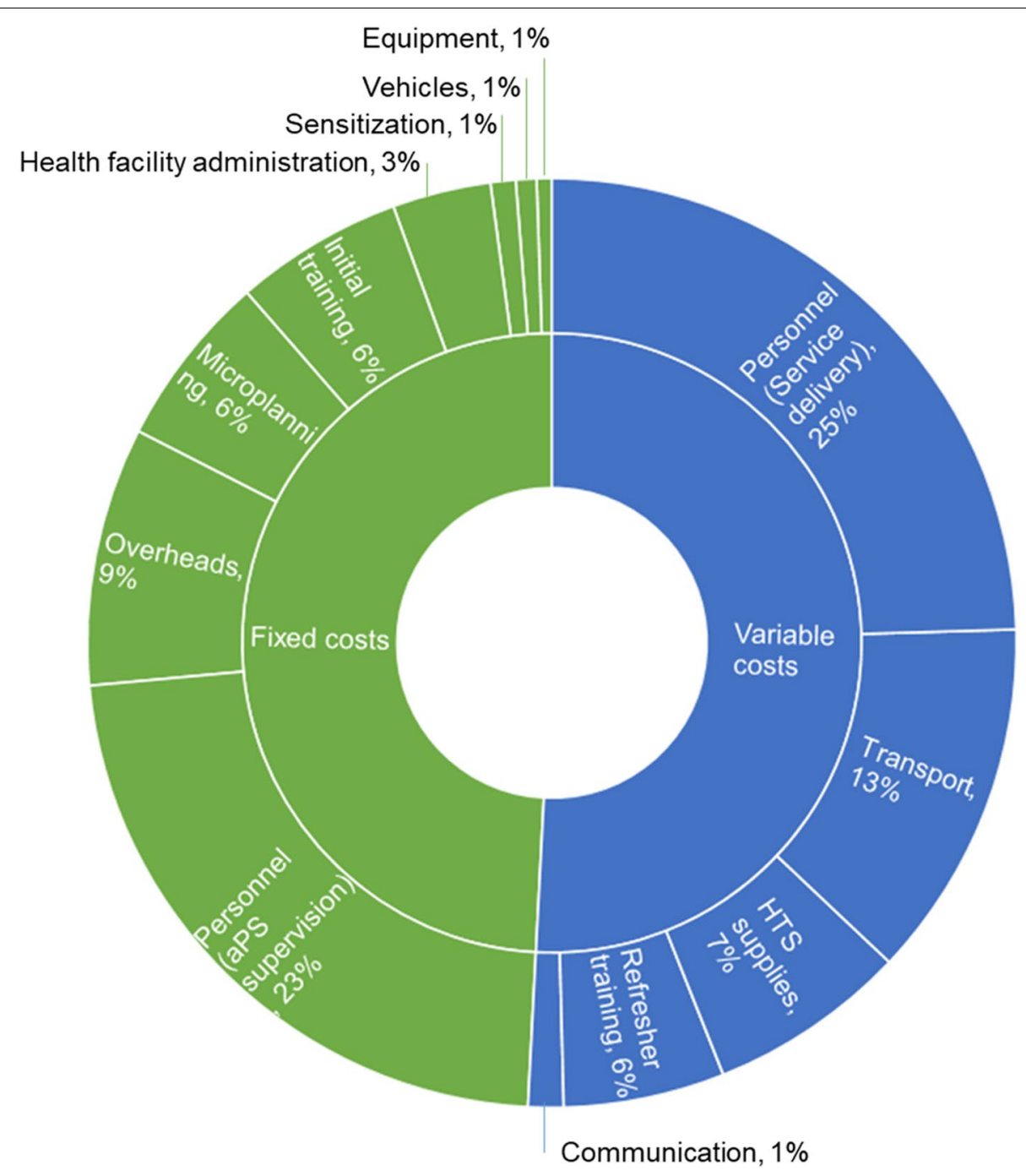

Fig. 2 Proportion of total incremental costs by input type for aPS integration.

randomized control trials (RCT) settings [4, 12]. In an aPS RCT targeting both male and female sex partners in Kenya, estimated costs per partner tested were \$48-55 using a program scenario with highly trained HTS providers i.e. health advisors [11]. In the same RCT, the cost of aPS ranged between $\$ 44.75$ and $\$ 53.07$ per client for nurse-based testing, and between $\$ 32.04$ and $\$ 33.72$ per client for CHW-based testing [12]. Our estimated average unit cost per MSP tested using regular HTS providers was slightly lower (as-implemented: $\$ 42.50, \mathrm{MOH}$-only scenario: \$31.59), though our cost estimates focused on MSPs only and not both male and female partners. Relative to other HIV prevention strategies e.g., HIV self-testing ( $\sim 10$ per client tested), voluntary medical male circumcision ( $\$ 66$ per procedure), and prevention of mother to child transmission (\$79 per client tested), aPS is likely an affordable, high-yield HIV prevention intervention that can be used to target relatively hardto-reach populations such as men [21-25]. Our team is currently evaluating a combined aPS and HIV self-testing strategy and its cost implications, the results of which will improve our understanding of combined HIV prevention strategies.

Compared to previous estimates, our unit costs may have been lower as we utilized HTS providers who are paid lower than health advisors or nurses used in prior aPS costing studies $[11,12]$. Though CHWs - who earn substantially lower salaries - are not yet approved to offer HTS and aPS in Kenya - task-shifting scenarios using this cadre have been shown to lower costs per partner tested and could potentially be used to offer aPS once approved $[12,26]$. Whether integrating aPS is sustainable will depend on availability of funds, priorities of the $\mathrm{MOH}$ and external funders, and willingness to scale-up 


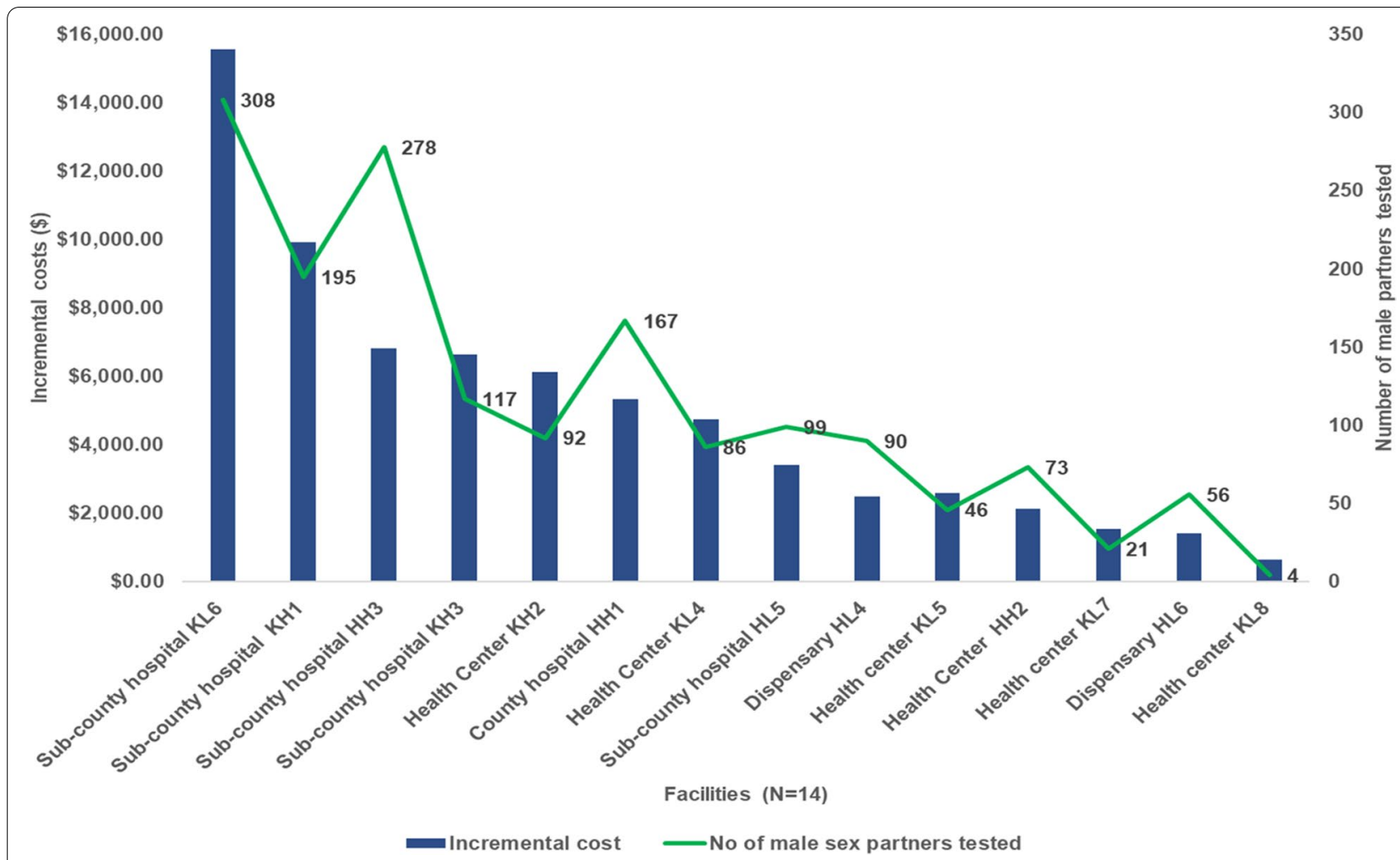

Fig. 3 Annual incremental cost of aPS in 14 facilities in Kisumu and Homa Bay County (As-implemented), 2019 USD

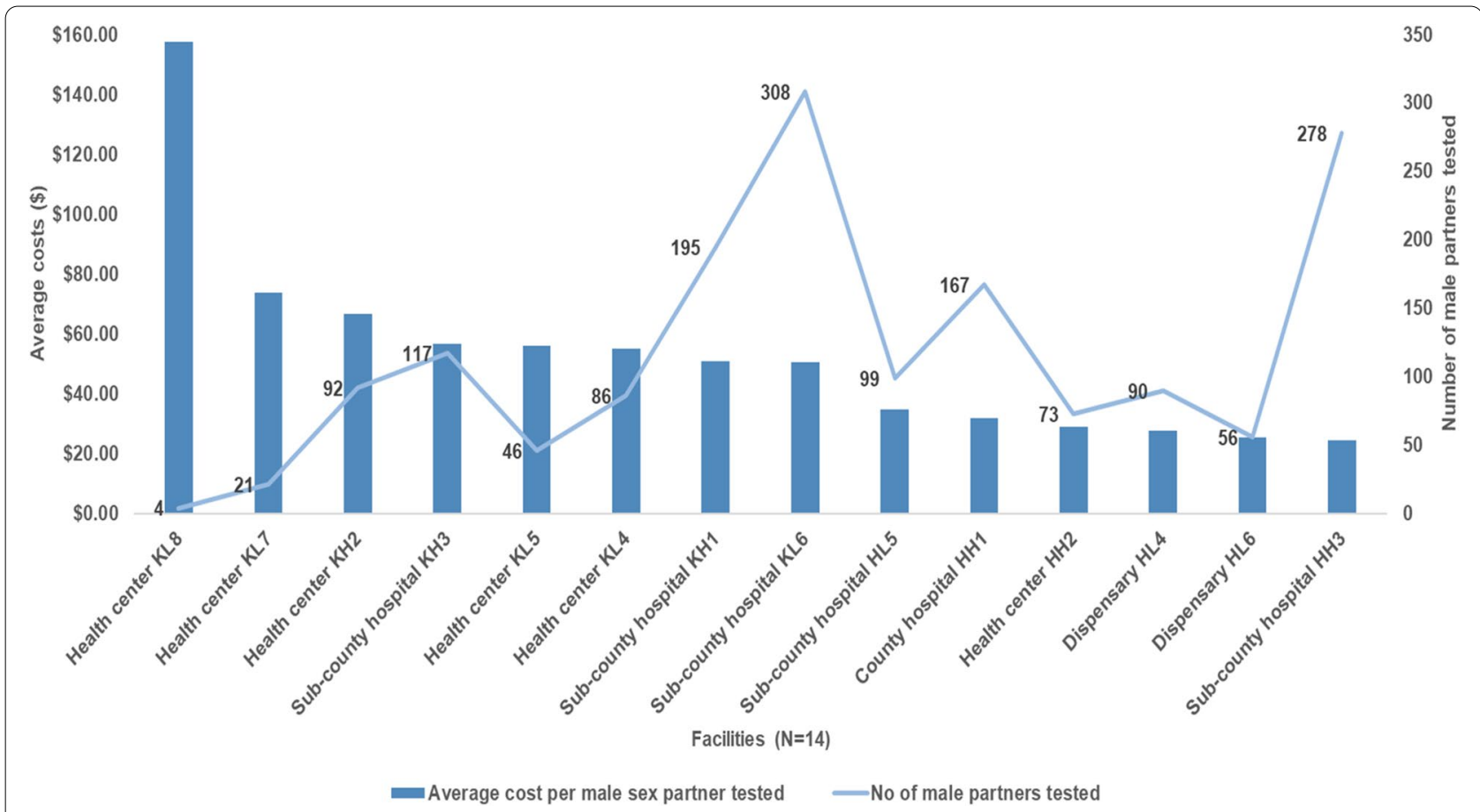

Fig. 4 Average cost of aPS per male sex partner tested in 14 health facilities in Kisumu and Homa Bay countries (As-implemented), 2019 USD 
and sustain aPS in the long-term. With declining funds and potential transition of HIV management from external funders to the government, key policy makers at national and county levels may have to adjust their budgets accordingly to ensure longevity of this intervention.

Similar to other aPS costing studies, personnel was a major cost driver accounting for $40-70 \%$ of total costs $[11,12]$. In an attempt to reduce personnel costs, the aPS scale-up project began using a hub-and-spoke model [27] in which HTS providers stationed at high volume facilities supported several lower volume facilities. While this occurred after our cost data collection had concluded, a hub-and-spoke strategy has the potential to improve efficiency given the lower average unit costs per MSP in high-volume facilities [28]. Other strategies to improve efficiency include community sensitization on aPS to increase awareness and encourage partners to uptake HTS at a facility, reducing personnel time and costs for phone and physical tracing [28]. Ministries of health may also consider transferring physical tracing to HTS providers stationed at health facilities closest to partners. However, this approach needs to be carefully reviewed in conjunction with the index clients due to concerns on privacy and confidentiality, and risks of intimate partner violence [5, 29].

There are several limitations in our study. By focusing only on MSPs, we were not able to estimate the cost of aPS for female sex partners. However, we anticipate most unit costs would be similar, apart from partner elicitation costs and physical tracing costs that may vary by target group. Secondly, our study focused on only 14 facilities in Kisumu and Homa Bay counties, which have the highest HIV prevalence in Kenya ( $>15 \%)$ and might not be representative of other counties or settings or easily generalizable [1]. However, costs in lower volume facilities in our study might be comparable to those in lower prevalence counties in Kenya. Third, we utilized a payer perspective and do not account for costs incurred or saved by participants receiving aPS in clinics or HTS in the community. Providing aPS in the community can reduce individual costs of time and transport to the facility; therefore, societal costs would be lower. Finally, we did not include ART costs in our analysis since these are covered by the HIV care and treatment program which is separate from the HIV/aPS program. In Kenya, ART costs are estimated to be between $\$ 70-\$ 215$ per person per year and these costs would need to be factored in for the additional HIV-positive clients reached through aPS [30].

Our study has several strengths. We evaluated the cost of integrating aPS into HTS programs within realworld settings, giving a realistic estimate of the implementation costs. We disaggregated costs to identify variations across facilities and propose strategies to improve cost efficiency. Finally, through detailed timeand-motion studies, we estimated the median time and cost of providing aPS during HTS, which will facilitate resource planning particularly human resource allocation and transport reimbursements.

\section{Conclusion}

This study contributes to the growing literature on the cost of integrating aPS, and while average facility costs are expected to increase when integrating aPS to HTS, this increase is within the expected range $[4,12$, 31]. As aPS is scaled-up, especially in resource-limited settings and as funding allocated to HTS shifts, additional research on cost-efficient strategies optimizing resource allocation during aPS is critically important.

\section{Supplementary Information}

The online version contains supplementary material available at https://doi. org/10.1186/s12913-022-07479-4.

Additional file 1.

\section{Acknowledgements}

The authors would like to acknowledge the contributions of the Kenya Ministry of Health, PATH-Kenya, the aPS scale-up team, healthcare workers, and the participants.

\section{Authors' contributions}

$C F, C L$, EK and BMW conceived and designed the study. CL and BMW developed the cost templates and coordinated study implementation. HL and EK facilitated data collection. BMW conducted data collection. BMW and CL analyzed the data with input from MS. BMW drafted the manuscript and the other authors reviewed and revised the manuscript. All authors approved the final draft for submission and publication.

\section{Funding}

This study was funded by the U.S. National Institutes of Health (NIH) NIAID R01Al134130. BMW and SM received support from the Fogarty International Center: D43 TW009580, D43 TW009783 and D43 TW010905. MS received support from NIMH K01MH115789. The funders had no role in the study design, data collection and analysis, decision to publish, or preparation of the article.

\section{Availability of data and materials}

The datasets used and/or analysed during the current study are available from the corresponding author on reasonable request.

\section{Declarations}

Consent for publication

Not applicable.

\section{Competing interests}

The authors declare that they have no competing interests.

\section{Author details}

${ }^{1}$ Department of Global Health, University of Washington, 325 9th Avenue, Box 359909, Seattle, WA 98104, USA. ${ }^{2}$ PATH- Kenya, Kisumu, Kenya. ${ }^{3}$ Kenya Medical Research Institute, Nairobi, Kenya. ${ }^{4}$ Ministry of Health, Nairobi,

Kenya. ${ }^{5}$ Department of Epidemiology, University of Washington, Seattle, USA.

${ }^{6}$ Department of Medicine, University of Washington, Seattle, USA. 
Received: 8 October 2021 Accepted: 30 December 2021

Published online: 14 January 2022

\section{References}

1. Kenya Population-based HIV Impact Assessment (KENPHIA) 2018 Preliminary Report [Internet]. [cited 31 Mar 2020]. Available from: https://phia. icap.columbia.edu/wp-content/uploads/2020/02/KENPHIA-2018_Preli minary-Report_final-web.pdf

2. WHO | Guidelines on HIV self-testing and partner notification [Internet]. WHO. [cited 2017 Jan 8]. Available from: http://www.who.int/hiv/pub/ vct/hiv-self-testing-guidelines/en/.

3. Wamuti BM, Erdman LK, Cherutich P, Golden M, Dunbar M, Bukusi D, et al. Assisted partner notification services to augment HIV testing and linkage to care in Kenya: study protocol for a cluster randomized trial. Implement Sci. 2015;10(1):23.

4. Sharma M, Smith JA, Farquhar C, Ying R, Cherutich P, Golden M, et al. Assisted partner notification services are cost-effective for decreasing HIV burden in western Kenya: a mathematical modeling analysis. AIDS. 2017.

5. Goyette M, Wamuti BM, Owuor M, Bukusi D, Maingi PM, Otieno FA, et al. Understanding barriers to scaling up HIV assisted partner services in Kenya. AIDS Patient Care STDs. 2016;30(11):506-11.

6. Henley C, Forgwei G, Welty T, Golden M, Adimora A, Shields R, et al. Scaleup and case-finding effectiveness of an HIV partner services program in Cameroon: an innovative HIV prevention intervention for developing countries. Sex Transm Dis. 2013;40(12):909-14.

7. Brown LB, Miller WC, Kamanga G, Nyirenda N, Mmodzi P, Pettifor A, et al. HIV partner notification is effective and feasible in sub-Saharan Africa: opportunities for HIV treatment and prevention. J Acquir Immune Defic Syndr. 2011:56(5):437-42.

8. Myers RS, Feldacker C, Cesár F, Paredes Z, Augusto G, Muluana C, et al. Acceptability and effectiveness of assisted human immunodeficiency virus partner services in Mozambique: results from a pilot program in a public, urban clinic. Sex Transm Dis. 2016:43(11):690-5.

9. Kahabuka C, Plotkin M, Christensen A, Brown C, Njozi M, Kisendi R, et al. Addressing the first 90: a highly effective partner notification approach reaches previously undiagnosed sexual partners in Tanzania. AIDS Behav. 2017:21(8):2551-60.

10. Sharma M, Kariithi E, Kemunto E, Otieno G, Lagat H, Wamuti B, et al. High acceptability of assisted partner notification services among HIV-positive females in Kenya: results from an ongoing implementation study. J Acquir Immune Defic Syndr. 2021;86(1):56-61.

11. Sharma M, Smith JA, Farquhar C, Ying R, Cherutich P, Golden M, et al Assisted partner notification services are cost-effective for decreasing HIV burden in western Kenya. AIDS. 2018;32(2):233-41.

12. Cherutich P, Farquhar C, Wamuti B, Otieno FA, Ng'ang'a A, Mutiti PM, et al. HIV partner services in Kenya: a cost and budget impact analysis study. BMC Health Serv Res 2018 [cited 2019 Feb 19]; 18. Available from: https:// www.ncbi.nlm.nih.gov/pmc/articles/PMC6142360/.

13. Grepin KA, Reich MR. Conceptualizing integration: a framework for analysis applied to neglected tropical disease control partnerships. PLoS Negl Trop Dis. 2008;2(4):e174

14. Kariithi E, Sharma M, Kemunto E, Lagat H, Otieno G, Wamuti BM, et al. Using assisted partner services for HIV testing and the treatment of males and their female sexual partners: protocol for an implementation science study. JMIR Res Protoc. 2021;10(5):e27262.

15. Guidelines for conducting adolescent HIV sexual and reproductive health research in Kenya. National AIDS and STI Control Programme (NASCOP) \& Kenya Medical Research Institute (KEMRI). 2018; 23:2015.

16. NASCOP. HIV testing services training manual [Internet]. [cited 2021 Dec 3]. Available from: https://www.nascop.or.ke/hiv-testing-services/

17. Drummond MF, Sculpher MJ, Claxton K, Stoddart GL, Torrance GW. Methods for the economic evaluation of health care programmes. Oxford: Oxford University Press; 2015.

18. Vassall A, Sweeney S, Kahn J, Gomez Guillen G, Bollinger L, Marseille E, et al. Reference case for estimating the costs of global health services and interventions. 2017;

19. OANDA. Average exchange rates [Internet]. [cited $22 \mathrm{Mar} 2021]$. Available from: https://www oanda com/fx-for-business/historical-rates
20. Liu W, Wamuti B, Owuor M, Lagat H, Kariithi E, Obong'o C, Mugambi M, Sharma M, Bosire R, Masyuko S, Farquhar C, Weiner BJ. "It is a process" - a qualitative evaluation of provider acceptability of HIV assisted partner services in western Kenya: experiences, challenges and facilitators [Poster]. 11th IAS Conference on HIV Science.

21. George G, Chetty T, Strauss M, Inoti S, Kinyanjui S, Mwai E, et al. Costing analysis of an SMS-based intervention to promote HIV self-testing amongst truckers and sex workers in Kenya. PLoS One. 2018:13(7):e0197305

22. Galárraga O, Wamai RG, Sosa-Rubí SG, Mugo MG, Contreras-Loya D, Bautista-Arredondo S, et al. HIV prevention costs and their predictors: evidence from the ORPHEA Project in Kenya. Health Policy Plan. 2017;32(10):1407-16

23. Rivera AS, Hernandez R, Mag-Usara R, Sy KN, Ulitin AR, O'Dwyer LC, et al. Implementation outcomes of HIV self-testing in low-and middle-income countries: a scoping review. PLoS One. 2021;16(5):e0250434.

24. Maheswaran H, Petrou S, MacPherson P, Choko AT, Kumwenda F, Lalloo DG, et al. Cost and quality of life analysis of HIV self-testing and facility-based HIV testing and counselling in Blantyre, Malawi. BMC Med. 2016;14(1):1-12.

25. Bulterys MA, Mujugira A, Nakyanzi A, Nampala M, Taasi G, Celum C, et al. Costs of providing HIV self-test kits to pregnant women living with HIV for secondary distribution to male partners in Uganda. Diagnostics. 2020;10(5):318.

26. Kenya Community Health Strategy 2020-2025 [Internet]. [cited 2021 Apr 22]. Available from: https://www.health.go.ke/wp-content/uploads/2021/ 01/Kenya-Community-Health-Strategy-Final-Signed-off_2020-25.pdf.

27. Elrod JK, Fortenberry JL. The hub-and-spoke organization design: an avenue for serving patients well. BMC Health Serv Res. 2017;17(1):25-33.

28. Siapka M, Remme M, Obure CD, Maier CB, Dehne KL, Vassall A. Is there scope for cost savings and efficiency gains in HIV services? A systematic review of the evidence from low-and middle-income countries. Bull World Health Organ. 2014;92:499-511AD.

29. Goyette MS, Mutiti PM, Bukusi D, Wamuti BM, Otieno FA, Cherutich P, et al. Hiv assisted partner services among those with and without a history of intimate partner violence in Kenya. J Acquir Immune Defic Syndr. 2018.

30. Duarte HA, Babigumira JB, Enns EA, Stauffer DC, Shafer RW, Beck IA, et al. Cost-effectiveness analysis of pre-ART HIV drug resistance testing in Kenyan women. EClinicalMedicine [Internet]. 2020 [cited 2021 Dec 3]; 22. Available from: https://www.thelancet.com/journals/eclinm/article/PIIS2 589-5370(20)30099-7/fulltext.

31. Rutstein SE, Brown LB, Biddle AK, Wheeler SB, Kamanga G, Mmodzi P, et al. Cost-effectiveness of provider-based HIV partner notification in urban Malawi. Health Policy Plan. 2014;29(1):115-26.

\section{Publisher's Note}

Springer Nature remains neutral with regard to jurisdictional claims in published maps and institutional affiliations.

Ready to submit your research? Choose BMC and benefit from:

- fast, convenient online submission

- thorough peer review by experienced researchers in your field

- rapid publication on acceptance

- support for research data, including large and complex data types

- gold Open Access which fosters wider collaboration and increased citations

- maximum visibility for your research: over $100 \mathrm{M}$ website views per year

At BMC, research is always in progress.

Learn more biomedcentral.com/submissions 